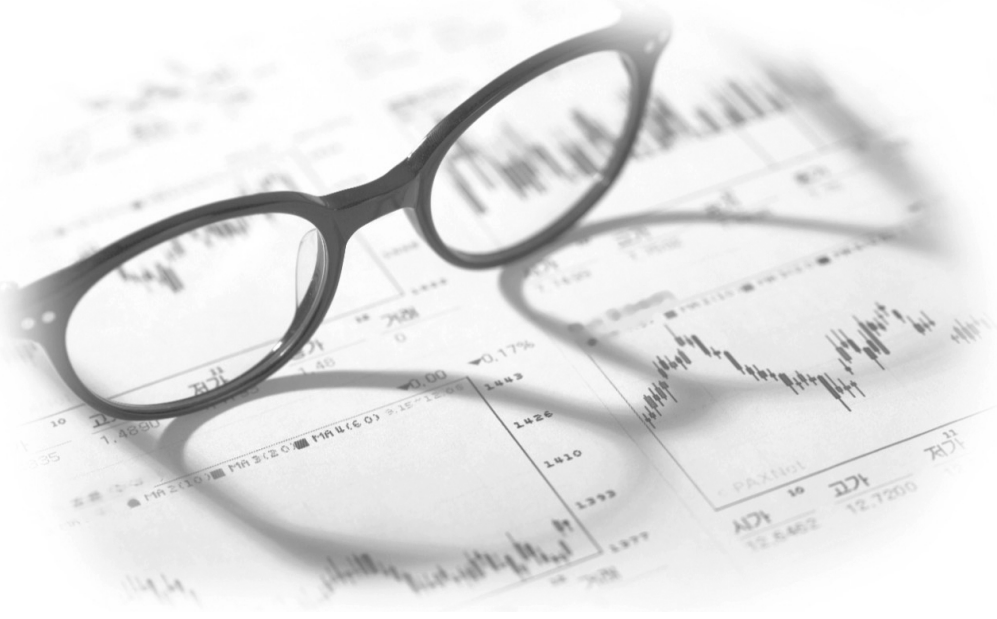

http://dx.doi.org/10.5045/kjh.2012.47.1.3

The Korean Journal of Hematology

Volume 47 • Number 1 • March 2012

Perspective

\section{Allogeneic stem cell transplantation for neuroblastoma}

\author{
Ki Woong Sung, M.D., Ph.D. \\ Department of Pediatrics, Samsung Medical Center, \\ Sungkyunkwan University School of Medicine, Seoul, Korea
}

\section{INTRODUCTION}

Neuroblastoma (NB) is the most common extracranial solid tumor in children. Although the prognosis of lowand intermediate-risk NB with conventional treatment modalities is excellent, the prognosis of high-risk NB with conventional treatment alone is very poor. The current standard treatment for high-risk NB consists of induction treatment (conventional chemotherapy and surgery with or without local radiotherapy), high-dose chemotherapy and autologous stem cell transplantation (HDCT/autoSCT) as a consolidation treatment, and 13 -cis-retinoid acid to reduce relapse from minimal residual disease. However, the eventfree survival rates are only $30-40 \%$, which is unsatisfactory. For this reason, a few clinical trials of tandem HDCT/ autoSCT, high-dose ${ }^{131}$ I-meta-iodobenzylguanidine (MIBG) treatment incorporated into HDCT/autoSCT, and anti-GD2 treatment after HDCT/autoSCT, are currently underway to improve the survival of high-risk NB patients. Furthermore, because about half of high-risk NB patients still die from treatment failure, allogeneic SCT (alloSCT) is being investigated as a potential curative option.

\section{AlloSCT AFTER RELAPSE}

Conventional chemotherapy is ineffective in patients who failed treatment, and they cannot tolerate additional intensive treatment because they have previously received intensive treatment. Therefore, in these patients, there is no realistic chance for cure using conventional treatment options alone. For this reason, alloSCT is being investigated as a potential curative treatment option, because it offers a graft-versus-tumor (GVT) effect not observed in autoSCT. Although a GVT effect has been demonstrated in patients with advanced NB who received alloSCT [1], regimenrelated mortality following standard alloSCT with an intensive myeloablative conditioning regimen may be extremely high in patients who have already been heavily treated.

\section{REDUCED-INTENSITY AlloSCT}

In recent years, several groups of investigators have developed reduced-intensity conditioning regimens that lead to engraftment of donor lymphoid and hematopoietic stem cells without the extra-hematopoietic toxicities of standard myeloablative conditioning, while conserving the graft-versus-leukemia (GVL) or GVT effect. The reduced regimen-related toxicity may make reduced-intensity alloSCT (RI alloSCT) particularly suitable for patients at high-risk of regimen-related mortality, especially previous HDCT/autoSCT recipients. In adults, striking GVT effects after RI alloSCT have been described in refractory breast cancer and renal cell carcinoma [2]. Currently, the number of studies employing RI alloSCT for NB is very small. However, early studies have suggested that it is a feasible approach and have shown GVT effects, which were confirmed by tumor disappearance after induction of acute graft-versus-host disease (GVHD) through withdrawal of immunosuppressive drugs or donor leukocyte infusion. However, control of GVHD using immunosuppressive drugs caused NB reappearance. The GVT effect could not control tumor proliferation, particularly in patients with a significant tumor burden at transplantation. Furthermore, it is

This is an Open Access article distributed under the terms of the Creative Commons Attribution Non-Commercial License (http://creativecommons.org/licenses/by-nc/3.0) which permits unrestricted non-commercial use, distribution, and reproduction in any medium, provided the original work is properly cited. 

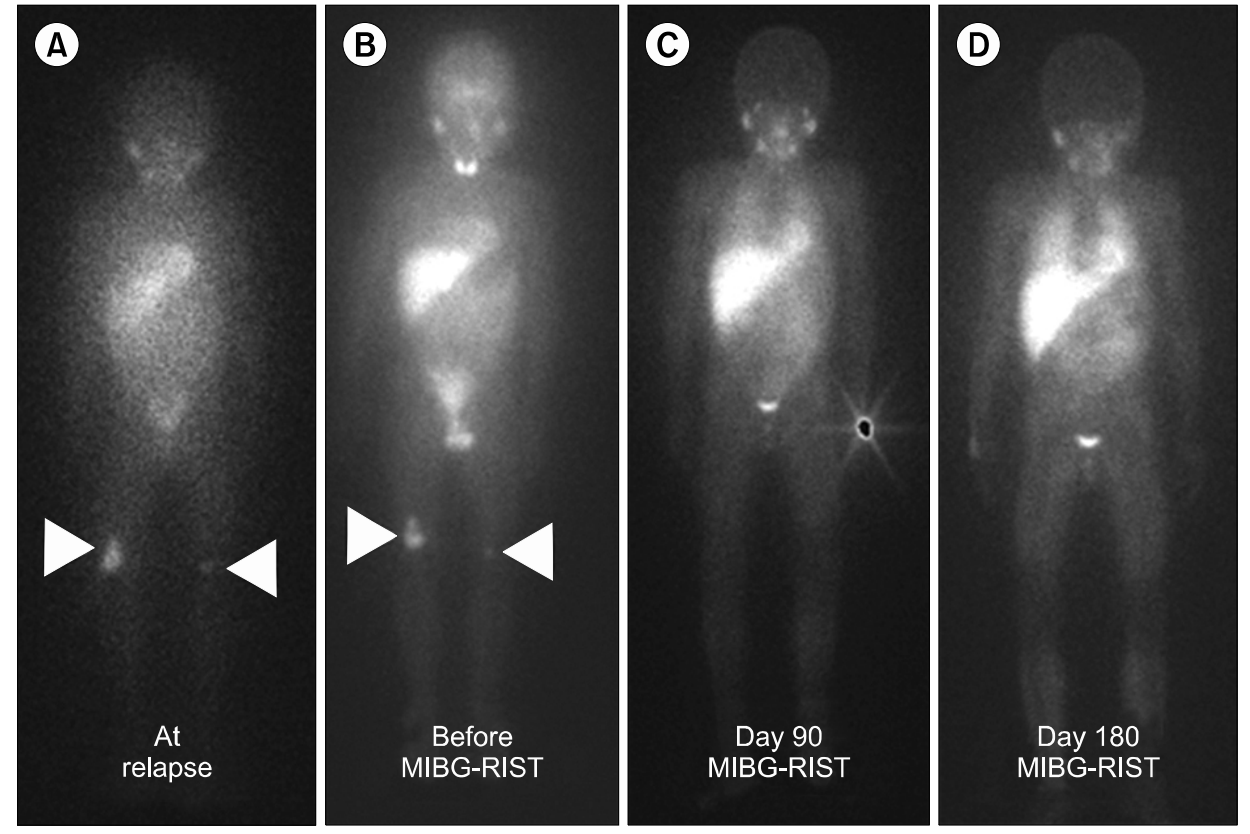

Fig. 1. Representative case. The patient had ${ }^{131}$ I-meta-iodobenzyIguanidine (MIBG) uptake at relapse after tandem HDCT/autoSCT (A) (arrow head). He still had MIBG uptake arrows after conventional salvage treatment (B) (arrow head). RI alloSCT was given after high-dose ${ }^{131}$ I-MIBG treatment $(18 \mathrm{mCi} / \mathrm{kg})$. Regimen-related toxicity was minimal and rapid engraftment and complete donor chimerism were successfully achieved. Grade I acute graftversus-host disease (GVHD) developed after withdrawal of immune suppression, and he had a moderate chronic GVHD. MIBG uptake was absent from day 90 and day 180 evaluations (C and D).

difficult to effectively reduce the tumor burden prior to transplantation using conventional treatment modalities. Therefore, a new treatment modality to effectively reduce tumor burden prior to transplantation, as well as a posttransplant adjuvant treatment to increase the GVT effect are needed to improve the outcome after RI alloSCT.

\section{REDUCTION OF TUMOR BURDEN PRIOR TO RI AlloSCT}

Because the GVT effect was not sufficient to prevent tumor progression in patients with significant tumor burdens, to effectively reduce tumor burden prior to transplantation, a new treatment modality is needed to improve the outcome after RI alloSCT. Unfortunately, an effective salvage regimen after relapse is not yet available. However, high-dose ${ }^{131}$ I-MIBG treatment might be an option for efficient reduction of tumor burden prior to RI alloSCT, because it has no significant toxicity other than hematologic toxicity, which can be overcome by alloSCT. Since investigators have successfully incorporated high-dose ${ }^{131} \mathrm{I}$-MIBG treatment into HDCT/autoSCT, a few investigators have begun to incorporate high-dose ${ }^{131} \mathrm{I}$-MIBG treatment into RI alloSCT and have shown that it is a feasible approach (Fig. 1) $[3,4]$.

\section{STEM CELL SOURCE}

Stem cell source is also an important issue to enhance the GVT effect. For many years, HLA-matched donors were the only types of donor routinely employed; however, recently, mismatched SCT was also shown to be feasible. Stronger GVHD and possibly stronger GVT effects are expected in unrelated or mismatched SCT than in related or matched SCT. Therefore, unrelated or mismatched SCT might be a preferred option, and not an alternative to related or matched SCT in specific subpopulations of patients, such as those with recurrent NB. Killer cell immunoglobulin-like receptor (KIR) ligand-mismatched SCT is also a possible option to enhance the GVT effect in NB, because NB cells do not express HLA class I antigens; therefore, NB cells could be an excellent target for NK cell alloimmunity.

\section{POST-SCT ADJUVANT TREATMENT}

Post-SCT adjuvant treatment might be another approach to increase the GVT effect. Donor leukocyte or NK cell infusion, NB-specific antibody treatment, or cytokine treatment after SCT might be options for enhancing the GVT effect against NB cells. The NK cell- or complementmediated immune response might be more important than the $\mathrm{T}$ cell-mediated immune response because NB cells generally do not express HLA class I antigens. Recently, Pérez-Martínez et al. reported their experience using KIR ligand-mismatched haploidentical SCT for 3 refractory metastatic solid tumors, including 1 NB [5]. This approach was feasible, and the GVT effect was also demonstrated.

\section{CURRENT CLINICAL TRIALS EMPLOYING RI AlloSCT}

A few different clinical trials employing combinations of the strategies mentioned above are currently underway (Table 1) [6-9]. Although the number of patients enrolled is small and follow-up duration is short, the preliminary results are encouraging. However, at present, we do not know which is the best strategy for achieving a successful outcome. Further studies will yield an answer. 
Table 1. Clinical trials employing reduced intensity allogeneic stem cell transplantation (RI alloSCT) for neuroblastoma (NB).

\begin{tabular}{|c|c|c|c|c|}
\hline Investigators & Eligibility & Treatment before alloSCT & Stem cell source & $\begin{array}{l}\text { Post-SCT } \\
\text { treatment }\end{array}$ \\
\hline Jubert et al. [6] & Refractory/relapsed & Conventional & Unrelated matched/mismatched CB & None \\
\hline Sung et al. [7] & Relapse after tandem autoSCT & Conventional & Related $>$ unrelated $>$ haploidentical & None \\
\hline Lang et al. [8] & Relapsed & Conventional & Haploidentical & $\pm \mathrm{DLI}$ \\
\hline Toporski et al. [4] & Refractory/relapsed & High-dose ${ }^{131}$ I-MIBG tx. & Haploidentical & $\pm \mathrm{DLI}$ \\
\hline Pérez-Martínez et al. [5] & Refractory & Conventional & KIR ligand mismatched haploidentical & None \\
\hline Lang et al. ${ }^{\text {a) }}$ & Refractory/relapsed & High-dose ${ }^{131}$ I-MIBG tx. & Haploidentical & Anti-GD2/IL-2 \\
\hline Sung et al. a) & Relapse after tandem autoSCT & High-dose $^{131}$ I-MIBG tx. & Related $>$ unrelated $>$ haploidentical & $\pm \mathrm{IL}-2$ \\
\hline Goi et al. [9] & High-risk & AutoSCT & Unrelated CB & None \\
\hline Takahashi et al.a) & Very high-risk or relapsed & AutoSCT & $\mathrm{KIR}$ ligand mismatched $\mathrm{CB}$ & None \\
\hline
\end{tabular}

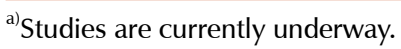

Abbreviations: autoSCT, autologous stem cell transplantation; MIBG, meta-iodobenzylguanidine; DLI, donor leukocyte infusion; KIR, killer cell immunoglobulin-like receptor; CB, cord blood.

\section{AlloSCT FOR NEWLY DIAGNOSED HIGH-RISK NB}

In the 1980s and the early 1990s, alloSCT was used as an alternative to autoSCT when autologous bone marrow had not been cleared of tumor or was impossible to harvest. Both the Children's Cancer Group and the European group reported no difference in relapse between those treated with autoSCT and alloSCT, but they reported a higher toxic death rate in the group treated with alloSCT. Since then, alloSCT has been largely abandoned. However, interest in alloSCT has been recently renewed by successful reports of RI alloSCT in solid tumors, and some promising experimental studies demonstrated a measurable antitumor immune response against NB. Recently, as an alternative to autoSCT, a few groups have studied alloSCT in an attempt to harness an immunotherapeutic effect. Early studies of alloSCT in children with newly diagnosed high-risk NB suggest that it is a feasible approach that may improve outcome. Colleagues at Nagoya University developed a novel SCT protocol to treat newly diagnosed very high-risk NB patients; KIR ligand-mismatched cord blood SCT is given after autoSCT. This novel prospective study is based on the hypothesis that the immunological effects of alloSCT will be most beneficial in children with minimal tumor burden early in the disease process prior to relapse.

\section{CONCLUSION}

Although RI alloSCT was shown to be feasible in patients who failed previous treatment, alloSCT for recurrent or high-risk NB remains investigational, and there are still many issues to be resolved. Therefore, at present, alloSCT is reserved for specific clinical trials assessing its immunomodulatory effect even though the advent of RI alloSCT has provided the expectation that it will reduce treatment-related mortality and allow for the detection of a therapeutic benefit.

\section{REFERENCES}

1. Inoue M, Nakano T, Yoneda A, et al. Graft-versus-tumor effect in a patient with advanced neuroblastoma who received HLA haplo-identical bone marrow transplantation. Bone Marrow Transplant 2003;32:103-6.

2. Blaise D, Bay JO, Faucher C, et al. Reduced-intensity preparative regimen and allogeneic stem cell transplantation for advanced solid tumors. Blood 2004;103:435-41.

3. Takahashi H, Manabe A, Aoyama C, et al. Iodine-131-metaiodobenzylguanidine therapy with reduced-intensity allogeneic stem cell transplantation in recurrent neuroblastoma. Pediatr Blood Cancer 2008;50:676-8.

4. Toporski J, Garkavij M, Tennvall J, et al. High-dose iodine131-metaiodobenzylguanidine with haploidentical stem cell transplantation and posttransplant immunotherapy in children with relapsed/refractory neuroblastoma. Biol Blood Marrow Transplant 2009;15:1077-85.

5. Pérez-Martínez A, Leung W, Muñoz E, et al. KIR-HLA receptor-ligand mismatch associated with a graft-versus-tumor effect in haploidentical stem cell transplantation for pediatric metastatic solid tumors. Pediatr Blood Cancer 2009;53:120-4.

6. Jubert C, Wall DA, Grimley M, Champagne MA, Duval M. Engraftment of unrelated cord blood after reduced-intensity conditioning regimen in children with refractory neuroblastoma: a feasibility trial. Bone Marrow Transplant 2011;46:232-7.

7. Sung KW, Park JE, Chueh HW, et al. Reduced-intensity allogeneic stem cell transplantation for children with neuroblastoma who failed tandem autologous stem cell transplantation. Pediatr Blood Cancer 2011;57:660-5.

8. Lang P, Pfeiffer M, Müller I, et al. Haploidentical stem cell transplantation in patients with pediatric solid tumors: preliminary results of a pilot study and analysis of graft versus tumor effects. Klin Padiatr 2006;218:321-6.

9. Goi K, Inukai T, Honna H, et al. Successful tandem (autologouscord blood) SCT in advanced neuroblastomas with highly amplified MYCN. Bone Marrow Transplant 2011;46:835-9. 